\title{
EPIDEMIOLOGY OF SEVERE SEPSIS IN THE EMERGENCY DEPARTMENT AND DIFFICULTIES IN THE INITIAL ASSISTANCE
}

\author{
Ederlon Rezende, João Manoel Silva Junior, Alexandre Marine Isola, Edvaldo
} Vieira Campos, Cristina Prata Amendola, Samantha Longhi Almeida

doi: $10.1590 / \mathrm{S1807-59322008000400008}$

Rezende E, Silva Junior JM, Isola AM, Campos EV, Amendola CP, Almeida SL. Epidemiology of severe sepsis in the emergency department and difficulties in the initial assistance. Clinics. 2008;63:457-64.

BACKGROUND: The aim of this study was to determine the occurrence rate, demographics, clinical characteristics, and outcomes of patients with severe sepsis admitted to the emergency department.

METHODS: A prospective study evaluating all patients admitted to the emergency department unit in a public hospital of tertiary complexity in a six-month period was conducted. During this period, the emergency team was trained to diagnose sepsis. Patients who met the diagnostic criteria for severe sepsis were followed until their discharge from the hospital.

RESULTS: A total of 5,332 patients were admitted to the emergency department, and 342 met the criteria for severe sepsis/septic shock. The median (interquartile range) age of patients was 74 (65-84) years, and 52.1\% were male. The median APACHE II and SOFA scores at diagnosis were 19 (15-25) and 5 (3-7), respectively. The median number of dysfunctional organ systems per patient was 2 (1-3). The median hospital length of stay was 10 (4.7-17) days, and the hospital mortality rate was $64 \%$. Only $31 \%$ of the patients were diagnosed by the emergency department team as septic. About $33.5 \%$ of the 342 severe sepsis patients admitted to the emergency department were referred to an ICU, with a median time delay of 24 (12-48) hours. Training improved diagnosis and decreased the time delay for septic patients in arriving at the ICU.

CONCLUSIONS: The occurrence rate of severe sepsis in the emergency department was 6.4\%, and the rate of sepsis diagnosed by the emergency department team as well as the number of patients transferred to the ICU was very low. Educational campaigns are important to improve diagnosis and, hence, treatment of severe sepsis.

KEYWORDS: Sepsis. Emergency Department. Occurrence. Epidemiology. Mortality. Training.

\section{INTRODUCTION}

Severe sepsis is a systemic inflammatory response secondary to infection and associated with the acute dysfunction of one or more organs. ${ }^{1}$ The disease is highly aggressive and may involve the progressive loss of function of several organs, but it should be considered reversible, especially if identified and treated early in its course.

It is estimated that 750,000 new cases of sepsis occur yearly in the USA, with roughly 215,000 deaths per year.

Hospital do Servidor Publico Estadual - Serviço de Terapia Intensiva, São Paulo/SP, Brazil.

Email: edvcampos@uol.com.br

Received for publication on February 12, 2008

Accepted for publication on April 28, 2008
In the last decade, its incidence has increased by about $91.3 \% .^{2}$ According to the BASES study, ${ }^{3} 27 \%$ of the patients referred to intensive care units in Brazil have severe sepsis, with a mortality rate of $47 \%$ at 28 days. Furthermore, sepsis substantially reduces the quality of life of those who survive. ${ }^{4}$

Several factors explain the increased incidence of sepsis, including the aging population, the increasing survival of patients who have cancer or are immunosuppressed, and the increasing numbers of invasive medical interventions. ${ }^{5}$

The septic patient is a constant challenge to the clinician and an early diagnosis is fundamental ${ }^{6}$ to its successful treatment. Even though a large volume of information has been collected about this topic, ${ }^{7-11}$ the lack of knowledge about the diagnostic criteria for sepsis by emergency teams is one of the greatest factors limiting its adequate treatment. ${ }^{12}$ 
When evaluating the efficacy of a specific treatment protocol for severe sepsis/septic shock in the emergency department (ED), Rivers et al. demonstrated a significant reduction in hospital mortality rate. ${ }^{13}$ Though septic patients admitted to the hospital are first examined in the ED, there are few hospitals that adopt a diagnostic approach with aggressive therapy in the ED.

Considering the lack of epidemiological studies involving severe sepsis/septic shock patients in the ED, the aim of the study was to determine the occurrence rate, demographic data, clinical characteristics, and outcomes of patients with severe sepsis admitted to the emergency department (ED) of a tertiary hospital.

\section{MATERIAL AND METHODS}

After approval by the Institution's Internal Review Board, which did not require obtaining patients' informed consent, the study was conducted in the hospital's Emergency Department, a 50-bed unit for severely ill patients. The medical team of the ED is composed of medical residents directed by clinicians and surgeons of several medical specialties. The ED does not have an emergency medical residency program. This hospital is a tertiary institution with 900 hospital beds and 42 ICU beds.

Patients with severe sepsis/septic shock were included based on the SCCM/ACCP Consensus 1991 criteria (Table 1). ${ }^{14}$ In an attempt to avoid seasonal differences, patients admitted to the ED during two distinct periods - February 1 to April 30, and July 1 to September 30, 2004 - were included.

The exclusion criteria were: patients younger than 18 years old and patients with terminal disease (moribund) who did not survive at least 24 hours after admission to the ED because of their underlying diseases (where management of their sepsis would not likely have helped).

Fellows specially trained to diagnose severe sepsis went to the ED four times a day to search for patients who fulfilled severe sepsis criteria. These patients were included in the study, and an arterial blood sample was collected in order to evaluate the arterial lactate level as a marker of organ dysfunction resulting from metabolic acidosis.

Instances where the ED team evaluated a chart referring to septicemia, generalized infection, sepsis, severe sepsis, or septic shock to make a diagnosis were considered diagnoses of sepsis. In addition, whether the ED team had prescribed any antibiotics as well as the amount of fluid administered in the first six hours was noted. If all care with regard to treatment of sepsis was performed by the ED team according to the Surviving Sepsis Campaign guidelines ${ }^{15,16}$, this was also considered to be a sepsis diagnosis.

In order to standardize data collection, the worst physiologic and laboratory values from the last 24 hours before study inclusion while patients were still in the ED were used to calculate the SOFA ${ }^{17}$ and APACHE $\mathrm{II}^{18}$ scores. In patients who were sedated, the Glasgow Coma Score was measured prior to sedation and registered in the chart. The researcher did not influence the decisions of the ED team.

Moreover, due to the unsatisfactory initial patient mortality results of the study, the institutional ethics committee and researchers decided to offer training to the ED team. The training provided instructions about sepsis diagnosis, according to the SSCCM/ACCP Consensus 1991 criteria $^{9}$ and it also provided instruction about sepsis treatment as recommended by the Surviving Sepsis Campaign guidelines. ${ }^{10-11}$ The training included lectures,

Table 1 - Inclusion Criteria

\begin{tabular}{|c|c|c|}
\hline Infection criteria & SIRS criteria & Organ or system dysfunction criteria \\
\hline $\begin{array}{l}\text { Highly likely or evident infectious focus based } \\
\text { on one or more criteria: } \\
\text { Leucocytes in otherwise sterile corporal liquid; } \\
\text { Viscus perforation; } \\
\text { Radiographic evidence of pneumonia plus } \\
\text { purulent sputum; } \\
\text { Clinical syndrome generally associated with } \\
\text { infection (e.g., ascending collagists). }\end{array}$ & $\begin{array}{l}\text { Systemic manifestations due to infection } \\
\text { characterized by at least two of the following } \\
\text { criteria: } \\
\text { Temperature }>38^{\circ} \mathrm{C} \text { or }<36^{\circ} \mathrm{C} \text {; } \\
\text { Respiratory Frequency }>20 \text { ripm, or } \mathrm{PaCO}_{2}< \\
32 \mathrm{~mm} \mathrm{Hg} \text {, or need of mechanical ventilation; } \\
\text { Cardiac Frequency }>90 \mathrm{bpm} \text {; } \\
\text { Leucometry }>12,000 \text { or }<4,000 \text { cells } / \mathrm{mm}^{3} \text { or } \\
\text { immature forms }>10 \% \text {. }\end{array}$ & $\begin{array}{l}\text { Presence of at least one dysfunctional target } \\
\text { organ: } \\
\text { Cardiovascular (hypotension or need for vasoac- } \\
\text { tive drugs); } \\
\text { Respiratory ( } \mathrm{PaO}_{2} / \mathrm{FiO}_{2}<250 \text { or need for venti- } \\
\text { latory support); } \\
\text { Renal (diuresis }<0.5 \mathrm{ml} / \mathrm{kg} / \mathrm{h} \text { ); } \\
\text { Neurological (acute change in the level of } \\
\text { consciousness); } \\
\text { Coagulation (platelets }<80,000 / \mathrm{mm}^{3} \text { or a fall of } \\
50 \% \text { relative to the greatest value in the previ- } \\
\text { ous three days); } \\
\text { Hepatic (total bilirubin }>1.2 \mathrm{mg} / \mathrm{dl} \text { except if } \\
\text { biliary pathology present); } \\
\text { Metabolic (acidosis and lactate elevated } 1.5 \\
\text { times the reference value). }\end{array}$ \\
\hline
\end{tabular}

*SIRS (Systemic Response Inflammatory Syndrome); $\mathrm{PaCO}_{2}, \mathrm{CO}_{2}$ arterial partial pressure; $\mathrm{PaO}_{2}, \mathrm{O}_{2}$ arterial partial pressure; FiO ${ }_{2}$, Oxygen inspiratory fraction; ripm, respiratory incursions per minute and beats per minute. 
folders, and pocket references. Patients were followed until hospital discharge or death.

After training the ED team, we checked whether sepsis diagnosis and treatment, according to the Surviving Sepsis Campaign guidelines ${ }^{15-16}$, had improved compared to diagnosis and treatment before training.

Collection and analysis of data were performed with Microsoft Excel and SPSS 13.0 software.

Demographic data were expressed as means \pm standard deviation, medians (interquartile interval), or percentages; 95\% confidence intervals were estimated to correctly classify outcomes. Means of quantitative variables were compared between two independent groups using the Student's $t$-test. Variables with nonsymmetrical distributions were evaluated using the Mann-Whitney test and the Friedman test. Nominal variables were shown as descriptive forms using tables of absolute and relative frequencies. Proportional comparisons were made using the Chi-square test.

Logistic regression was performed using "backward" analysis to identify independent risk factors and to control for confounding effects (mutually adjusted variables). Variables considered statistically significant $(p<0.05)$ in the univariate analysis were considered as candidates using the multiple regression model. Every statistical test was twotailed, and a significance level of 0.05 was used.

\section{RESULTS}

During the study period, 5332 patients were admitted to the ED and $369(6.9 \%)$ of them fulfilled the criteria for severe sepsis, but of those, only $342(6.4 \%)$ patients met inclusion criteria and $27(0.5 \%)$ patients were excluded because they presented with serious underlying diseases. The occurrence rate of severe sepsis in the ED during the study is presented in Figure 1.

Patients with severe sepsis admitted to the ED had a mean age of $73.7 \pm 13.5$ years, and $52.6 \%$ were male. The median APACHE II and SOFA scores were 19 (15-25) and 5 (3-7), respectively. Patients had a median of 2 (1-3) dysfunctional organs (Table 1). In addition, 106 (31\%) patients had septic

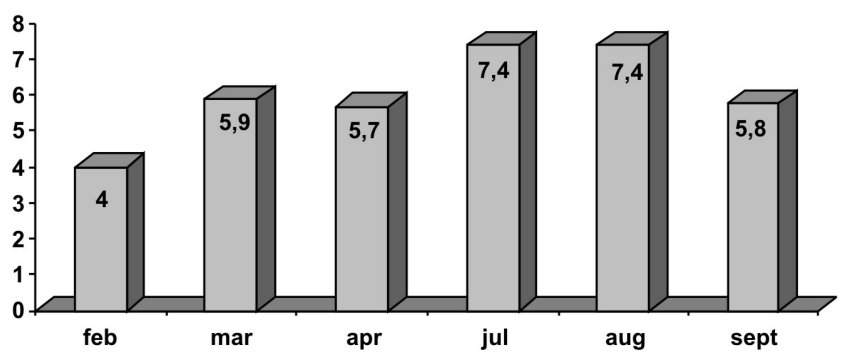

Figure 1 - Severe sepsis occurrence in patients admitted to the ED during the period of the study. Columns indicate the percentage of all patients shock. The median length of hospital stay was 10 (4.7-17) days, and the hospital mortality rate was $64 \%$.

The main infection sites were: lower respiratory tract, $\mathrm{n}=194(56.7 \%)$, followed by urinary tract, $\mathrm{n}=72(21.1 \%)$ and intra-abdominal infections, $\mathrm{n}=37(10.8 \%)$. Twenty-seven (7.9\%) patients presented with catheter-related bloodstream infections, catheter insertion site infections, or infection in other sites, such as the central nervous system, skin, blood, bones, joints or the heart. There was no defined site of infection in $12(3.5 \%)$ patients.

The main physiologic and laboratory variables at the inclusion in the study are presented in Table 2.

Table 2 - Main physiologic and laboratory variables at inclusion

\begin{tabular}{ll}
\hline Variables & Characteristics \\
\hline Heart rate (rpm) & $96.5 \pm 17.3$ \\
Systolic arterial pressure $(\mathrm{mm} \mathrm{Hg})$ & $117.7 \pm 27.6$ \\
Mean arterial pressure $(\mathrm{mm} \mathrm{Hg})$ & $86.9 \pm 19.7$ \\
Diastolic pressure $(\mathrm{mm} \mathrm{Hg})$ & $71.5 \pm 17.3$ \\
First arterial lactate $(\mathrm{mmol} / \mathrm{l})$ & $2.4(1.6-3.6)$ \\
Glycemia $(\mathrm{mmol} / \mathrm{L})$ & $7.6(5.7-9.9)$ \\
Leucocytes $\left(\mathrm{cells} / \mathrm{mm}^{3}\right)$ & $13,330(9160-18,200)$ \\
Platelets $\left(\mathrm{cells} / \mathrm{mm}^{3}\right)$ & $207,000(154,000-286,000)$ \\
\hline
\end{tabular}

Results are presented in mean \pm standard deviation or median (25\%-75\%)

At the time of inclusion, $39.8 \%$ of patients showed one dysfunctional organ or system, whereas $27.8 \%$ of patients presented two dysfunctions; three dysfunctional organs or systems were seen in $20.7 \%$; four or five dysfunctions were present in $9.4 \%$ of patients; and six were present in $2.3 \%$ of patients.

About $90 \%$ of the patients received antibiotics prescribed by the ED physicians, but the amount of administered fluids (crystalloids) during the first six hours was only 500 (5001006.25) $\mathrm{mL}$. No colloids were prescribed during the first six hours of treatment.

Among the 342 patients with severe sepsis in the ED, only $115(33.5 \%)$ were referred to the ICU.

The variables considered statistically different between survivors and nonsurvivors were: age, male gender, APACHE II and SOFA scores, pulmonary and urinary infectious focus, arterial lactate level, number of organ dysfunctions (metabolic, cardiovascular, neurological, renal, hepatic and respiratory dysfunction), as well as diagnosis by the ED team with referral to the ICU, and mean, systolic, and diastolic arterial pressures (Table 3).

In the logistic regression, only the discriminative variables from the univariate analysis were considered. Age, 
Table 3 - Comparison between survivors and non-survivors

\begin{tabular}{|c|c|c|c|c|c|c|}
\hline \multirow{2}{*}{$\begin{array}{l}\text { Variables } \\
\text { Age }\end{array}$} & \multirow{2}{*}{$\begin{array}{c}\begin{array}{c}\text { Non Survivors } \\
(\mathrm{n}=219)\end{array} \\
76.1 \pm 12.3\end{array}$} & \multirow{2}{*}{$\begin{array}{c}\text { Survivors }(n=123) \\
69.5 \pm 14.7\end{array}$} & \multirow[t]{2}{*}{ OR } & \multicolumn{2}{|c|}{$95 \% \mathrm{CI}$} & \multirow{2}{*}{$\begin{array}{c}\mathrm{p} \\
.000\end{array}$} \\
\hline & & & & 3.66 & 9.52 & \\
\hline \multicolumn{7}{|l|}{ Gender } \\
\hline Males & $57.7 \%$ & $43.4 \%$ & 1.73 & 1.11 & 2.70 & .011 \\
\hline Females & $42.3 \%$ & $56.6 \%$ & & & & \\
\hline APACHE II & $21.5(18.0-28.0)$ & $16.0(13.0-20.0)$ & & & & .000 \\
\hline SOFA & $5.0(4.0-8.0)$ & $4.0(3.0-5.0)$ & & & & .000 \\
\hline \multicolumn{7}{|l|}{ Infectious Site } \\
\hline Pulmonary & $60.9 \%$ & $49.2 \%$ & 0.47 & 0.29 & 0.78 & .005 \\
\hline Abdominal & $10.5 \%$ & $11.5 \%$ & 0.91 & 0.45 & 1.85 & .944 \\
\hline Urinary & $18.2 \%$ & $26.2 \%$ & 0.55 & 0.32 & 0.93 & .036 \\
\hline Others & $6,8 \%$ & $9,8 \%$ & 0.65 & 0.30 & 1.42 & .437 \\
\hline Unknown & $3,6 \%$ & $3,3 \%$ & 1.10 & 0.34 & 3.61 & .871 \\
\hline Number of dysfunctional organs/systems & $2.0(1.0-3.0)$ & $1.0(1.0-2.0)$ & & & & .000 \\
\hline Acidosis & $35.5 \%$ & $23.0 \%$ & 1.88 & 1.13 & 3.11 & .014 \\
\hline Cardiovascular & $37.7 \%$ & $18.9 \%$ & 2.47 & 1.46 & 4.17 & .001 \\
\hline Coagulation & $10.9 \%$ & $12.3 \%$ & 0.88 & 0.45 & 1.76 & .730 \\
\hline Liver & $18.6 \%$ & $12.3 \%$ & 1.49 & 0.80 & 2.80 & .207 \\
\hline Neurological & $50.9 \%$ & $32.0 \%$ & 2.13 & 1.34 & 3.38 & .001 \\
\hline Renal & $30.0 \%$ & $18.0 \%$ & 1.83 & 1.07 & 3.14 & .026 \\
\hline Respiratory & $51.8 \%$ & $42.6 \%$ & 1.56 & 0.99 & 2.44 & .050 \\
\hline \multicolumn{7}{|l|}{ Sepsis diagnosis by ED Team } \\
\hline Yes & $35.0 \%$ & $23.8 \%$ & 1.65 & 1.00 & 2.71 & .048 \\
\hline No & $65.0 \%$ & $76.2 \%$ & & & & \\
\hline \multicolumn{7}{|l|}{ ICU admission } \\
\hline Yes & $39.5 \%$ & $23.0 \%$ & 2.28 & 1.38 & 3.76 & .001 \\
\hline No & $60.5 \%$ & $77.0 \%$ & & & & \\
\hline Heart Rate & $97.9 \pm 21.1$ & $93.9 \pm 18.3$ & & 0.24 & 8.70 & .063 \\
\hline Systolic pressure & $113.2 \pm 26.9$ & $125.8 \pm 27.1$ & & -17.95 & -5.97 & .000 \\
\hline Mean pressure & $84.1 \pm 19.8$ & $91.9 \pm 18.6$ & & -11.65 & -3.05 & .001 \\
\hline Diastolic pressure & $69.6 \pm 17.7$ & $74.9 \pm 16.0$ & & -8.84 & -1.24 & .009 \\
\hline Arterial lactate & $2.6(1.7-3.9)$ & $2.0(1.4-3.1)$ & & & & .001 \\
\hline Glycemia & $7.3(5.6-10.0)$ & 7.7(5.7-9.8) & & & & .713 \\
\hline
\end{tabular}

$\mathrm{N}=$ Number of patients, ICU= intensive care unit, $\mathrm{OR}=$ odds ratio (the $\mathrm{OR}$ for the continuous quantitative variables represents the risk increased or decreased for each one unit), 95\% IC = confidence interval. Results are presented as mean \pm standard deviation or median $(25 \%-75 \%)$; the chi-square test was used for nominal variables, the Student's $t$-test for means and the Mann-Whitney test for medians.

APACHE II, male gender, systolic pressure and number of organ dysfunctions were independent variables for the risk of death in the ED (Table 4).

The diagnosis of severe sepsis defined by the ED team was made mainly in patients that had a large number of organ dysfunctions - generally, four, five or six (Figure 3).

In the first three months of the study, only $15.8 \%$ of patients with severe sepsis were diagnosed correctly by the medical team from the ED.

Considering this low rate, which demonstrated the ED team's difficulty in correctly diagnosing sepsis, we started training the ED team in order to improve their skills in this area. After this training, $38.5 \%$ of severe septic patients were diagnosed in the ED ( $<<0.001$; Figure 2). The median time between admission to the ED and arrival in the ICU was 24 (12-48) hours; hence, the time to arrive in the ICU decreased 
Table 4 - Multivariate analysis of mortality-independent factors

\begin{tabular}{lcccc}
\hline Variables & $\mathrm{P}$ & $\mathrm{OR}$ & $95 \% \mathrm{CI}$ & \\
\hline Age & .000 & 1.044 & 1.021 & 1.068 \\
Male gender & .002 & 1.870 & 1.088 & 3.215 \\
Site of infection & .509 & & & \\
Lung & .526 & 1.594 & .378 & 6.726 \\
Urinary & .799 & .820 & .183 & 3.691 \\
Diagnosis of sepsis (yes) & .771 & 0.891 & .483 & 1.643 \\
Arterial lactate (mm Hg) & .702 & 1.033 & .875 & 1.219 \\
Systolic pressure (mm Hg) & .000 & .981 & .971 & .991 \\
Diastolic pressure (mm Hg) & .852 & 1.003 & .975 & 1.031 \\
Mean pressure (mm Hg) & .852 & 1.004 & .963 & 1.047 \\
Number of dysfunctional & .001 & 1.656 & 1.230 & 2.230 \\
organs/systems & & & & \\
APACHE II & .000 & 1.152 & 1.095 & 1.211 \\
SOFA & .196 & 1.100 & .952 & 1.270 \\
\hline
\end{tabular}

$\mathrm{OR}=$ odds ratio (the $\mathrm{OR}$ for the continuous quantitative variables represents the risk increase or decrease for each one unit). $95 \%$ IC $=$ confidence interval.

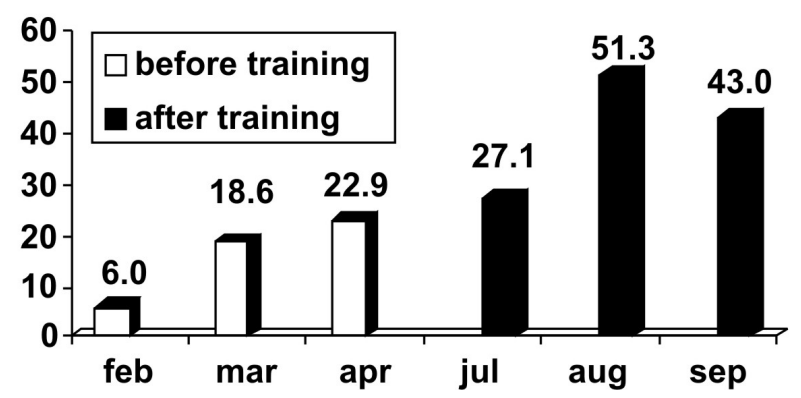

Figure 2 - Percentage of diagnosis of severe sepsis by the ED team before and after training. Chi-square test $(\mathrm{p}<0,001)$

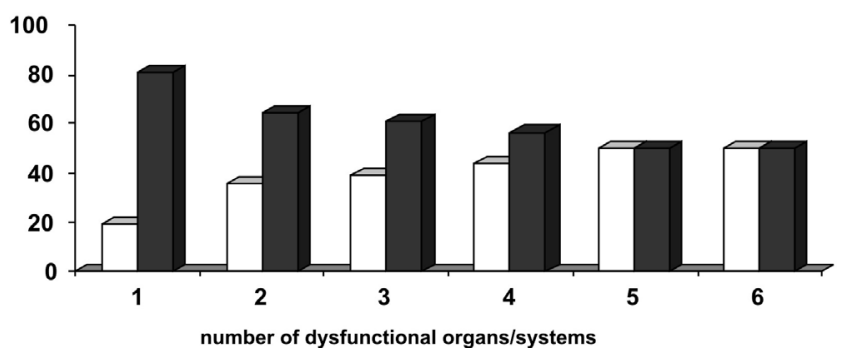

Figure 3 - Percentage of patients with a diagnosis of sepsis made by the ED team according to the number of dysfunctional organs. White columns: percentage of patients with sepsis diagnosis; black columns: percentage of patients without diagnosis. Chi-square test $(\mathrm{p}=0,006)$

after training, with a median delay time of 48 hours before training and 12 hours after training (Figure 4). In addition, the mortality rate decreased significantly, from $71.4 \%$ before training to $50.9 \%$ after training $(\mathrm{p}=0.03)$.

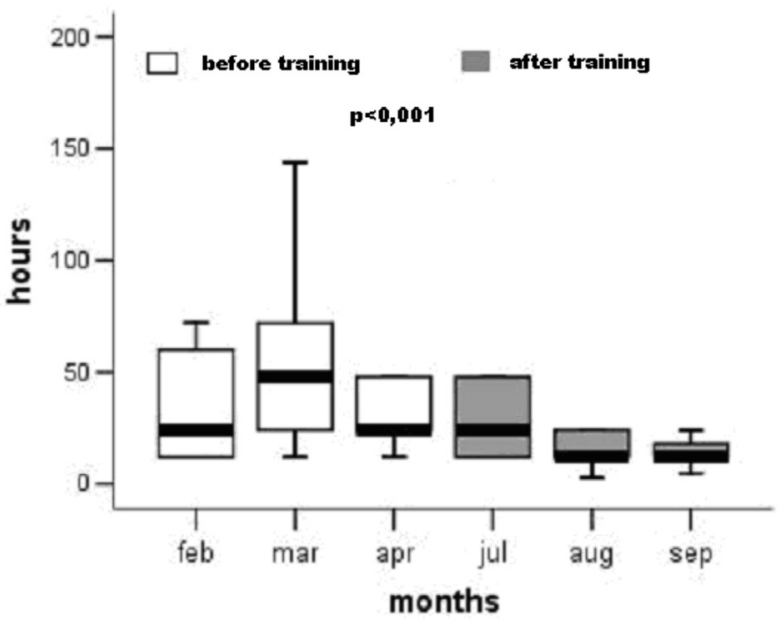

F Igure 4 - iviedians and interquartile intervals of time (in nours) to aamission to the ICU during study, before and after training. Friedman test

\section{DISCUSSION}

Our study is the first prospective cohort study in Brazil performed exclusively in an emergency department to evaluate the characteristics and prognostic factors of this population. Of the 5532 patients admitted to the ED, 342 had a diagnosis of severe sepsis. Thus, the occurrence of the disease was $6.4 \%$ in adult patients. Only $34 \%$ of those patients were admitted to the ICU, indicating a low rate of sepsis treatment in the ICU.

Sepsis is a major reason for admission to the ICU and is the leading cause of death in noncoronary ICU patients and a common cause of death among hospitalized patients. ${ }^{19}$ Many sepsis cases are belatedly recognized, and patients are treated inadequately by physicians outside the ICU who are not familiar with the symptoms and signs of the disease.

Sepsis acquires a greater epidemiological importance every year, and the vast majority of studies report rates of 10 \pm 4 cases per 100 admissions to the ICU. ${ }^{20}$

Several epidemiological reports on sepsis have appeared in recent years, after the publication of the definitions of the ACCP/SCCM consensus in $1991 .{ }^{9}$ However, those studies were exclusively done in the ICU setting. Our study is different, as it allowed us to analyze patients with severe sepsis prior to ICU admission and allowed for inclusion of all non-terminal patients who died in the ED. This is not observed in epidemiological studies that have evaluated the incidence of sepsis in ICU patients only.

In comparison to our study, a French study ${ }^{21}$ with 11828 selected patients found 742 severe sepsis cases and an incidence rate of $14.6 \%$. A study in Oceania with 5878 patients reported 691 cases of severe sepsis and an incidence rate of $11.8 \% .^{22}$ In addition, there is a United Kingdom (UK) 
study involving 56673 selected patients, with an incidence rate of $27.1 \% .^{23}$

In the USA, the rate of sepsis treatment was 82.7 cases per 100,000 in inhabitants in the period between 1979 and 1984, rising to 240.4 between 1995 and 2000. ${ }^{23}$ In Brazil, epidemiological data are scarce. According to the BASES study $^{3}$ of the southern and southeastern regions of the country, 241 of 1383 patients admitted to ICUs (27.3\%) were treated in an ICU for severe sepsis.

The severe sepsis mortality rate has ranged from 18 and $52 \%$ of the cases in different studies. ${ }^{15}$ This rate has probably been underestimated because the majority of the patients are not admitted to the ICU and are not even diagnosed by the ED team. In this study, we observed that the in-hospital mortality rate was $64 \%$, greater than that detected in previous reports, with a median hospital length of stay very close to the global median of 10 days. In other words, even when the incidence of severe sepsis is not neglected, the mortality rate can be very high.

In Brazil $^{3}$ and the $\mathrm{UK}^{23}$, the admission rates of severely septic patients to ICUs are proportionally high. These countries have a smaller number of available ICU beds than the USA. ${ }^{24}$ Consequently, the admission to the ICU of patients that require more attention, such as septic shocked patients with multiple organ dysfunctions, diminishes the number of beds available for patients who have less severe sepsis. By comparison, in the USA, patients are admitted early to ICUs, with fewer requirements of critical care facilities, such as mechanical ventilation. They have low mortality rates (17.9 to $27.8 \%){ }^{25,26}$ Thus, in Brazil and the UK, ICU beds are spared for sicker patients, with greater resulting mortality rates $(47 \%)$. The $\mathrm{ED}$, therefore, can be an important setting in which to treat sepsis. This is particularly important in countries with scarce resources and few available ICU beds as there, patients must be treated earlier, often while still in the ED.

In the present study, patients with severe sepsis had a mean age of 74 years. In contrast, the majority of studies have only considered patients treated in the ICU, who were around 65 years old. Patients with severe sepsis are aged and frequently have co-morbidities. Angus et al. ${ }^{27}$ suggested that age is an important independent factor of mortality in patients with sepsis. In the present study, age as a variable was strongly related to death. The fact that patients in the present study were older than in other studies suggests the possibility that a natural process is occurring: older patients with sepsis admitted to the ED have fewer functional reserves and progress quickly to poor outcomes, without admission to the ICU. This is a serious issue when the number of available ICU beds is low.

We also found at the ED that systolic pressure was an important factor in mortality and that patients with lower systolic pressures had a worse prognosis, even though we need to keep in mind that the clinical importance of this factor is low in our study because each increase of $1 \mathrm{mmHg}$ in systolic pressure decreased the risk of death by only $0.02 \%$. Interestingly, systolic pressure was better than the mean pressure in predicting mortality. Le Gall et al. developed a severity score known as LODS (Logistic Organ Dysfunction System) ${ }^{28}$ in which they used logistic regression to demonstrate that systolic pressure has great importance in evaluating cardiovascular function. Moreover, the systolic pressure is the most important determinant of the left cardiac systolic volume and has also been considered as a variable of preload for some researchers. ${ }^{29,30}$ Thus, close monitoring of systolic pressure could be useful in patients with severe sepsis.

In addition, several studies have described gender differences in adult mortality related to cardiovascular events, with several studies suggesting that females may have lower mortality. ${ }^{31}$ In this study, a higher mortality was seen in males than females. This result suggests that sex steroids could modulate the inflammatory response and outcome after injury.

Furthermore, patients with one or two $(2.1 \pm 1.1)$ dysfunctional organs and a median SOFA score of 5 (3-7) were the most prevalent in our study. In the present study, the prognosis worsened as the number of dysfunctional organs increased, as demonstrated by the multivariate analysis (odds ratio $=1.656)$. A French study involving 35 ICUs revealed that patients with severe sepsis and two or more dysfunctional organs had a greater mortality rate. ${ }^{32}$

In our study, the ability of the ED team to diagnose severe sepsis was poor (only $31 \%$ of the septic patients were diagnosed). Diagnosing sepsis as soon as possible is fundamental to the quick initiation of treatment, as demonstrated by Rivers et al. ${ }^{8}$

In the present study, the diagnosis of severe sepsis was made more frequently in the most severely ill patients, who had a greater number of organ dysfunctions. Poeze et al., in an international study with 1058 physicians, observed that the definitions of sepsis in the 1991 ACCP/SCCM consensus are not well known compared to those of other specialties, resulting in a poor ability to diagnose sepsis. ${ }^{33}$ The symptoms and signs are easily confounded by other diseases, making diagnosis very difficult. Sepsis tends to be detected only when multiple organ dysfunctions are seen, compromising the proper treatment.

Thus, early markers of the disease are necessary, and several studies have noted the usefulness of tissue perfusion markers such as serum arterial lactate, ${ }^{34,35}$ central or mixed venous saturation, ${ }^{8}$ base excess, ${ }^{36} \mathrm{PCO}_{2}$ gap,${ }^{37}$ or metabolic 
variables, such as glycemia as potential early markers. ${ }^{38}$ Vital signs such as arterial pressure or diuresis are later markers and are often unchanged, even in patients in septic shock. ${ }^{39}$

The incidence of severe sepsis in the studied population was $6.4 \%$, but the ED team diagnosed it in less than onethird of the affected patients.

Thus, the severe sepsis diagnosis level in the ED was very low $(15.8 \%)$. After training, the ability to accurately diagnose sepsis improved to $38.5 \%$. The in-hospital mortality rate in this sample was large, and only one-third of the patients were referred to the ICU. Furthermore, possible seasonal interferences were avoided in this study, because they already had been reported in a previous research. ${ }^{40}$

The epidemiological studies that have considered the incidence of severe sepsis treated in ICUs may have evaluated only a small part of a major problem. This could be explained based on findings observed in our study, that many patients with severe sepsis frequently are admitted to the ED without being referred to the ICU. This problem could be even more serious in developing countries with limited resources.

The major limitation of our study is its unicenter characteristic. However, tertiary teaching hospitals frequently receive the majority of the most severe sepsis cases, including patients with multiple organ dysfunctions secondary to sepsis. Another limitation is that the collection of comorbidities was not foreseen, and therefore not planned for in our protocol.

\section{CONCLUSION}

The occurrence rate of severe sepsis in the ED was $6.4 \%$. Age, APACHE II score, male gender, number of organ dysfunctions, and systolic pressure were independent factors associated with a greater risk of mortality in patients with severe sepsis in our study.

Educational campaigns are important to improving diagnosis and hence the treatment of severe sepsis. These campaigns must include ED training, so that teams responsible for the initial evaluation can adequately recognize and treat patients during the so called golden hour.

\section{ACKNOWLEDGEMENTS}

We thank Renata Andrea P. Pereira and Luciano N. Sanches for their great contributions to the study.

\section{REFERENCES}

1. Bone RC, Grodzin CJ, Balk RA. Sepsis: a new hypothesis for pathogenesis of the disease process. Chest. 1997;112:235-43.

2. Linde-Zwarble WT, Angus DC, Carcillo J, Lidicker J, Clermont G, Pinsky MR. Age- specific incidence and outcome of sepsis in the US. Crit Care Med 1999; 27: Suppl 1: A33. Abstract.

3. Silva E, Almeida PM, Sogayar ACB, Mohovic T, Oliveira SCL, Janiszewski M, et al. Brazilian Sepsis Epidemiological Study (BASES study). Crit Care. 2004;8:R251-R260.

4. Heyland DK, Hopman W, Coo H, Tranmer J, McColl MA. Long-term health-related quality of life in survivors of sepsis: Short Form-36: a valid and reliable measure of health-related quality of life. Crit Care Med. 2000;28:3599-605.

5. Knaus WA, Sun X, Nystrom O, Wagner DP. Evaluation of definitions for sepsis. Chest 1992;101:1656-62.

6. Balk RA, Bone RC. The septic syndrome: definition and clinical implications. Crit Care Clin. 1989;5:1-8.

7. Mazza BF, Machado FR, Mazza DD, Hassmann V. Evaluation of blood transfusion effects on mixed venous oxygen saturation and lactate levels in patients with SIRS/sepsis. Clinics. 2005;60:311-316.

8. Park M, Azevedo LCP, Maciel AT, Pizzo VR, Noritomi DT, Cruz Neto LM da. Evolutive standard base excess and serum lactate level in severe sepsis and septic shock patients resuscitated with early goal-directed therapy: still outcome markers? Clinics. 2006;61:47-52
9. Chandra A, Enkhbaatar P, Nakano Y, Traber LD, Traber DL. Sepsis: emerging role of nitric oxide and selectins. Clinics. 2006;61:71-76.

10. Angele MK, Frantz MC, Chaudry IH. Gender and sex hormones influence the response to trauma and sepsis - potential therapeutic approaches. Clinics. 2006;61:479-88.

11. Nakagawa NK, Jukemura J, Aikawa P, Nogueira RA, Poli-de-Figueiredo LF, Sannomiya P. In vivo observation of mesenteric leukocyteendothelial interactions after cecal ligation/puncture and surgical sepsis source control. Clinics. 2007;62:321-26.

12. Vincent JL, Abraham E, Annane D, Bernard G, Rivers E and Van den Berghe G. Reducing mortality in sepsis: new directions. Crit Care. 2002, 6 (suppl 3): S1-S18.

13. Rivers E, Nguyen B, Havstad S, Ressler J, Muzzin A, Knoblich B, et al. Early goal-directed therapy in the treatment of severe sepsis and septic shock. N Engl J Med. 2001;345:1368-77.

14. American College of Chest Physicians/Society of Critical Care Medicine Consensus Conference: definitions for sepsis and organ failure and guidelines for the use of innovative therapies in sepsis. Crit Care Med. 1992;20:864-874.

15. Dellinger RP, Carlet JM, Masur H, Gerlach H, Calandra T, Cohen J, et al. Surviving Sepsis Campaign Management Guidelines Committee: Surviving Sepsis Campaign guidelines for management of severe sepsis and septic shock. Crit Care Med. 32:858-873, 2004. 
16. Dellinger RP, Levy MM, Carlet JM, Bion J, Parker MM, Jaeschke R, et al. Surviving Sepsis Campaign: International guidelines for management of severe sepsis and septic shock: 2008. Intensive Care Med. 2008. $34 ; 1: 17-60$.

17. Vincent J-L, de Mendonça A, Cantraine F, Moreno R, Takala J, Suter P, et al. Use of the SOFA score to assess the incidence of organ dysfunction/ failure in intensive care units : results of a multicenter, prospective study. Crit Care Med. 1998;26:1793-1800.

18. Knaus WA, Zimmerman JE, Wagner DP, Draper EA, Lawrence DE. APACHE - acute physiology and chronic health evaluation: a physiologically based classification system. Crit Care Med. 1981;9:5917.

19. Moss M, Martin GS. A global perspective on the epidemiology of sepsis. Intensive Care Med. 2004;30:527-29.

20. Linde-Zwirble W, Angus CD. Severe sepsis epidemiology: sampling, selection, and society. Epub. 2004;8:222-26.

21. Brun-Buisson C, Meshaka P, Pinton P, Vallet B. EPISEPSIS: a reappraisal of the epidemiology and outcome of severe sepsis in French intensive care units. Intensive Care Med. 2004;30:580-88.

22. Finfer S, Bellomo R, Lipman J, French C, Dobb G, Myburgh J. Adultpopulation incidence of severe sepsis in Australian and New Zealand intensive care units. Intensive Care Med. 2004;30:589-96.

23. Padkin A, Goldfrad C, Brady AR, Young D, Black N, Rowan K. Epidemiology of severe sepsis occurring in the first 24 hours in ICU in England, Wales and Northern Ireland. Med. 2003;31:2332-38.

24. Martin GS, Mannino DM, Eaton S, Moss M. The epidemiology of sepsis in the United States from 1979 through 2000. N Engl J Méd. 2003;348:1546-54.

25. Knaus WA, Wagner DP, Draper EA, Zimmerman JE, Bergner M, Bastos PG, et al. The APACHE III prognostic system. Risk prediction of hospital mortality for critically ill hospitalized adults. Chest. 1991;100:161936.

26. Rowan KM, Kerr JH, Major E, McPherson K, Short A, Vessey MP. Intensive Care Society's APACHE II study in Britain and Ireland - II: outcome comparisons of intensive care units after adjustment for case mix by the American APACHE II method. BMJ. 1993;307:977-81.

27. Angus DC, Linde-Zwirble WT, Lidicker J, Clermont G, Carcillo J, Pinsky MR. Epidemiology of severe sepsis in the United States: Analysis of incidence, outcome, and associated costs of care. Crit Care Med. 2001;29:1303-10.
28. Le Gall JR, Klar J, Lemeshow S, Saulnier F, Alberti C, Artigas A, et al. The Logistic Organ Dysfunction system. A new way to assess organ dysfunction in the intensive care unit. ICU Scoring Group. JAMA. $1996 ; 276: 802-10$

29. Perel A, Pizov R, Cotev S. Systolic blood pressure variation is a sensitive indicator of hypovolume intravascular in ventilated dogs subjected to graded hemorrhage. Anesthesiology. 1987;67:498-502.

30. Michard F, Teboul JL. Using heart-lung interactions to assess fluid responsiveness during mechanical ventilation. Crit Care. 2000;4:28289.

31. Trentzsch H, Stewart D, Maio A. Genetic background conditions the effect of sex steroids on the inflammatory response during endotoxic shock. Crit Care Med. 2003; 31:232-36.

32. Guidet B, Aegerter P, Gauzit R, Meshaka P, Dreyfuss D, on behalf of the CUB-Réa Study Group. Incidence and Impact of Organ Dysfunctions Associated With Sepsis. Chest. 2005;127:942-51.

33. Poeze M, Ramsay G, Gerlach H, Rubulotta F and Levy Mitchel. An international sepsis survey: a study of doctors' knowledge and perception about sepsis. Crit Care. 2004, 8:R409-R413.

34. Weil MH, Afifi AA. Experimental and clinical studies on lactate and pyruvate as indicators of the severity of acute circulatory failure (shock). Circulation. 1970;41:989-1001.

35. Shapiro NI, Howell MD, Talmor D, Nathanson LA, Lisbon A, Wolfe RE, et al. Serum Lactate as a Predictor of Mortality in Emergency Department Patients with Infection. Ann Emerg Med. 2005; 4:52428.

36. Smith I, Kumar P, Molloy S, Rhodes A, Newman PJ, Grounds RM, et al. Base excess and lactate as prognostic indicators for patients admitted to intensive care. Intensive Care Med. 2001; 27:74-83.

37. Mekontso-Dessap A, Castelain V, Anguel N, Bahloul M, Schauvliege F, Richard C, et al. Combination of venoarterial $\mathrm{PCO} 2$ difference with arteriovenous $\mathrm{O} 2$ content difference to detect anaerobic metabolism in patients. Intensive Care Med. 2002;28:272-7.

38. Van den Berghe G, Wouters P, Weekers F, Verwaest C, Bruyninckx F, Schetz M, et al. Intensive insulin therapy in the critically ill patients. N Engl J Méd. 2001;345:1359-67.

39. Meregalli A, Oliveira RP, Friedman G. Occult hypoperfusion is associated with increased mortality in hemodynamically stable, highrisk, surgical patients. Crit Care. 2004;8:R60-R65.

40. Danai PA, Sinha S, Moss M, Haber MJ, Martin GS. Seasonal variation in the epidemiology of sepsis. Crit Care Med. 2007; 35:410-15. 